\title{
Jogo como estratégia de ensino Tematizando a prática de lutas na escola
}

\section{Games as teaching strategies}

Addressing striving practices in schools

\section{El juego como estrategia de enseñanza \\ Tematizando la práctica de luchas en la escuela}

\section{MARCOS PAULO VAZ DE CAMPOS PEREIRA*}

Universidade do Estado de Santa Catarina, Florianópolis- SC, Brasil.

ALEXANDRA FOLLE*

Universidade do Estado de Santa Catarina, Florianópolis- SC, Brasil.

ALCYANE MARINHO ${ }^{* * *}$

Universidade do Estado de Santa Catarina, Florianópolis- SC, Brasil.

ÍRIS DANTAS DA MOTA****

Universidade do Estado de Santa Catarina, Florianópolis- SC, Brasil.

\section{GELCEMAR OLIVEIRA FARIAS ${ }^{* * * * *}$}

Universidade do Estado de Santa Catarina, Florianópolis- SC, Brasil.

RESUMO: O objetivo do estudo éidentificar o processo de ensino das lutas por meio do jogo nas aulas de Educação Física escolar. Foram

\footnotetext{
* $\quad$ Mestre em Ciências do Movimento Humano pela Universidade do Estado de Santa Catarina. E-mail: $<$ marcosp.pereira46@gmail.com>.

** Doutora em Educação Física e Professora Adjunta da Universidade do Estado de Santa Catarina. E-mail: <afolle_12@hotmail.com>.

** Doutora em Educação Física e Professora Adjunta da Universidade do Estado de Santa Catarina. E-mail: <alcyane.marinho@hotmail.com>.

*** Mestre em Ciências do Movimento Humano pela Universidade do Estado de Santa Catarina. E-mail: <irisdantas83@gmail.com>. $* * * * * \quad$ Doutora em Educação Física e Professora Adjunta da Universidade do Estado de Santa Catarina. E-mail:
$<$ fariasgel@hotmail.com>.
} 
entrevistados seis professores de Educação Física. Na análise de conteúdo, foram elencadas as categorias: conhecimento do professor sobre o conteúdo lutas; jogo como uma estratégia de ensino; e sistematização do conteúdo lutas. Os resultados apresentaram ojogo como uma estratégia de ensino por meio de jogos de oposição, das dimensões dos conteúdos, da dimensão atitudinal e somente pelo jogo. O jogo na escola se torna um meio apropriado para tematizar lutas na escola, vistas suas potencialidades no desenvolvimento integral do aluno e no trato pedagógico do professor.

Palavras-chave: Artes marciais. Ensino. Educação Física.

ABSTRACT: The main objective of these studies is to identify the teaching process of such striving actions through games within schools Physical Education classes. In the content analysis, the categories were listed as the teacher's knowledge about the subjects on striving actions; games as teaching strategies; and systematization of the content on striving actions. The results introduced games as a teaching strategy through opposition games, from content dimensions, attitudinal dimension, and only through the games themselves. Games in school become an appropriate mean to address striving practices in schools, given their potential for the full development of students and the pedagogical treatment of teachers.

Keywords: Martial arts. Teaching. Physical Education.

RESUMEN: El objetivo del estudio es identificar el proceso de enseñanza de las luchas a través del juego en las clases de educación física en la escuela. Seis profesores de educación física fueron entrevistados. En el análisis de contenido, se enumeraron las categorías: conocimiento del profesor sobre el contenido luchas; juego como estrategia de enseñanza; y sistematización del contenido luchas. Los resultados presentaron el juego como una estrategia de enseñanza a través de juegos de oposición, de las dimensiones de los contenidos, de la dimensión actitudinal y solo a través del juego. El juego en la escuela se convierte en una forma apropiada de tematizar las luchas en la escuela, dado su potencial para el desarrollo integral del estudiante y el tratamiento pedagógico del profesor.

Palabras clave: Artes marciales. Enseñanza. Educación Física. 


\section{Introdução}

s lutas compõem um leque cultural pautado na diversidade de suas mani-
festações difundidas pelo mundo (REID; CROUCHER, 1983), sendo
contextualizadas em diferentes cenários que propiciam a aquisição de seus valores e de seus conhecimentos. Estas manifestações derivam das artes marciais e dos esportes de combate, compondo uma dimensão polissêmica de contextos (CORREIA; FRANCHINI, 2010), sendo que um deles é a escola. Local este em que as lutas são dimensionadas como conteúdo da Educação Física escolar, corroborando como um dos conteúdos da cultura corporal do movimento humano (PEREIRA et al., 2017).

O conteúdo lutas apresenta restrições na sua utilização no ambiente escolar, algumas pautadas pelo professor, no desenvolvimento do conteúdo no cotidiano, quer pela não vivência como praticante ou pela não aquisição do conhecimento na formação inicial (NASCIMENTO; ALMEIDA, 2007; CORREIA; FRANCHINI, 2010; RUFINO; DARIDO, 2012; ALENCAR et al., 2015). Outras restrições podem estar relacionadas a fatores como a relação das lutas com a violência e a especificidade do conhecimento atrelados à figura de um especialista em algum tipo de luta, no caso, um professor faixa preta (OLIVIER, 2000; BREDA et al., 2010; GALATTI; CIRINO; SCAGLIA, 2015). Tais argumentos distanciam as lutas da escola e ainda corroboram para que o conteúdo seja pouco explorado.

Quand o o conteúdo de lutas é tematizado na escola, alguns fatores ainda são evidenciados, como as limitações dos professores em apresentar apenas alguma modalidade aos alunos ou através de pesquisas divulgadas na internet ou por vídeos (VECCHIO; FRANCHINI, 2006; RUFINO; DARIDO, 2012; CORREIA, 2015). Outras formas de apresentar o conteúdo são por práticas analíticas, apenas por gestos técnicos e repetições isoladas (SCAGLIA; GOMES, 2011; GALATTI; CIRINO; SCAGLIA, 2015). Em suma, o conteúdo pode ser tematizado sem o cuidado em sistematizar e encontrar alguma estratégia de ensino que contemple uma gama de manifestações (RUFINO; DARIDO, 2012; PEREIRA et al., 2017) que pode dimensionar pelo seu ensino nas aulas de Educação Física.

A luta na escola pode apresentar inúmeros benefícios aos alunos, devido às contribuições motoras e cognitivas durante o combate (GOMES et al., 2010; CIRINO; PEREIRA; SCAGLIA, 2013). Para o desenvolvimento integral do aluno, mediante a tematização das lutas escola, o jogo pode ser uma estratégia para superar as restrições e as limitações dos professores quanto ao seu ensino. Considerado uma atividade voluntária imprevisível, que contém jogadores, regras pré-estabelecidas e a relação entre espaço e tempo (CAILLOIS, 1990), é uma alternativa pedagógica para tematizar o conteúdo nas aulas de Educação Física.

Nesse ínterim, requer compreender o conceito atribuído ao jogo para se ter uma visão magna do fenômeno. Para isso, o ato de jogar é que irá transpor seus significados para o processo pedagógico (SUITS, 1967). Ademais, a partir de quem joga, consegue-se 
estudar os aspectos motores, afetivos, sociais e morais, princípios indispensáveis à formação integral dos alunos (CHÂTEAU, 1987).

Investigadores preocupados com a temática lutas na escola e com o ensino destas por meio do jogo têm se debruçado em investigar propostas pedagógicas, relatos de experiência e estratégias para tematizar esse conteúdo (OLIVIER, 2000; SCAGLIA; GOMES, 2011; CIRINO; PEREIRA; SCAGLIA, 2013; PEREIRA et al., 2017). No entanto, estudos de campo sobre o processo de ensino das lutas ainda são recentes e escassos, carecendo de investigações empíricas no cenário da Educação Física escolar. Assim, faz-se necessário compreender como é realizado o processo de ensino do conteúdo lutas, utilizando o jogo enquanto estratégia de ensino, além de outros fatores referentes ao conteúdo lutas que interferem ou potencializam a tematização na escola. Partindo destas considerações, o objetivo deste estudo é identificar o processo de ensino das lutas por meio do jogo nas aulas de Educação Física escolar.

\section{Procedimentos metodológicos}

O estudo caracterizado como descritivo, apresenta como análise dos dados a abordagem qualitativa e foi aprovado pelo Comitê de Ética em Pesquisa com Seres Humanos da Universidade do Estado de Santa Catarina, sob o parecer n. 2.380.744/2017, sendo o recorte de um projeto de pesquisa intitulado "As lutas no ensino da Educação Física escolar: uma proposta metodológica por meio de redes complexas dos jogos".

Fizeram parte da investigação seis professores de escolas estaduais pertencentes à Coordenadoria Regional da Grande Florianópolis de Santa Catarina, os quais desenvolviam as lutas em suas aulas. Os professores investigados possuem graduação em Educação Física e atuam na educação básica, sendo quatro professoras e dois professores. Quanto à formação acadêmica, dois professores possuem pós-graduação stricto sensu, três possuem pós-graduação lato sensu e um professor apresenta formação na graduação. Com o objetivo de manter o anonimato, cada participante foi classificado da seguinte maneira: professor 1; professor 2; professor 3; professor 4; professor 5; e professor 6.

Como instrumento de pesquisa, foi adotada a entrevista semiestruturada, configurando uma estratégia que busca o recolhimento de informações aprofundadas, conforme a relação do pesquisador com o participante investigado (NEGRINE, 1999). A entrevista foi estruturada, considerando três temas geradores: conhecimento do professor sobre o conteúdo lutas; jogo como estratégia de ensino; e sistematização do conteúdo lutas.

Ao iniciar a coleta, foi apresentado ao participante o roteiro da entrevista e explanada a intenção do estudo (objetivos), de modo que todas as dúvidas fossem esclarecidas. Posteriormente à transcrição das entrevistas, estas foram encaminhadas por e-mail, 
individualmente, para cada professor, de modo a obter a validação do conteúdo. $\mathrm{O}$ tempo de duração de cada entrevista totalizou aproximadamente uma hora e meia.

Para auxiliar na organização e na análise dos dados coletados, buscou-se os recursos do software NVivo 9.2. Por sua vez, para a análise das informações, foi adotada a técnica da análise de conteúdo, seguindo as orientações de Bardin (1977), por meio das três etapas: pré-análise (tratando-se da leitura de cada entrevista transcrita); codificação (ordenando unidades de registro, em consonância ao objetivo do estudo); e categorização (referindo-se à organização das respostas dos participantes). As categorias do estudo foram elencadas a priori, sendo que as subcategorias que emergiram das falas dos entrevistados foram elencadas a posteriori, conforme o quadro 1.

\section{Quadro 1 - Categorias e subcategorias da análise das entrevistas}

\begin{tabular}{l|l}
\hline CATEGORIAS & SUBCATEGORIAS \\
\hline $\begin{array}{l}\text { Conhecimento do professor sobre o } \\
\text { conteúdo lutas }\end{array}$ & Conceito de lutas \\
& Receios do professor em aplicar o conteúdo de lutas \\
\hline Jogo como uma estratégia de ensino & Jogos de oposição como estratégia de ensino \\
& Benefícios de jogo ensinar lutas por meio do jogo \\
\hline Sistematização do conteúdo lutas & Período de tematização do conteúdo de lutas \\
& Tipos de sistematização do conteúdo de lutas \\
& Sistema de avaliação do conteúdo de lutas \\
\hline
\end{tabular}

\section{Resultados e discussão}

\section{Conhecimento do professor sobre o conteúdo lutas}

As narrativas dos professores serão apresentadas tendo a intenção de compreender como conceituaram as lutas e como refletiram sobre os paradigmas impostos pela sociedade, que implicam o ensino do conteúdo. A relação das lutas com a violência se torna um paradigma recorrente durante a tematização do conteúdo. O ensino fundamental foi o contexto de intervenção na escola que os professores entrevistados atuavam e em suas aulas o conteúdo lutas é tematizado, considerando o jogo como uma das estratégias possíveis para a aprendizagem dos alunos. Desta maneira, os professores, ao conceituarem as lutas, foram unânimes em classificá-las como uma forma de confronto. 
Além da ideia de confronto, a literatura apresenta que, para classificar as lutas, torna-se necessário observar o contexto no qual estão inseridas, pois podem estar relacionadas à ação de lutar pela vida por algum ou com algum oponente (RUFINO; DARIDO, 2012). Para tanto, outras vertentes podem indicar que as lutas estão relacionadas à sobrevivência humana, ao exercício militar, mas, também, às tradições culturais, religiosas e filosóficas da humanidade (REID; CROUCHER, 1983). É certo que os significados das lutas se manifestam por seu contexto, pois Gomes (2008) apresenta que o termo lutas se aplica sempre quando houver um combate, com ou sem armas, mas sempre contra um oponente, assim como relata o Professor 2, quando destaca que a "Luta é uma forma de confronto, onde a meta é vencer o oponente".

Essa constatação também corrobora com os demais participantes, que, além de classificarem e conceituarem as lutas como uma forma de confronto, mencionaram as modalidades de lutas, como apresenta o Professor 3, "Conheço várias modalidades de lutas, como o judô, o jiu-jitsu, a capoeira, tem diversas!". Pode-se mencionar, ainda, que o resultado em relação ao conceito de lutas se materializa pelo conhecimento que os participantes apresentaram sobre o conteúdo, pois, as lutas estão presentes na sociedade e suas modalidades derivam das artes marciais e dos esportes de combate (CORREIA; FRANCHINI, 2010; CORREIA, 2015). Talvez este seja um dos motivos que permitem que o professor faça esta relação com as modalidades.

Por outro lado, os seis participantes relataram que não possuem receios em aplicar o conteúdo, porém, foram feitas algumas ponderações, como menciona um dos participantes,

Nunca tive receio em tematizar lutas, faz pouco tempo que estou dando aula, e nunca tive problema nenhum, mas sempre tem aquele pensamento das pessoas que a luta vai gerar briga, deixar os alunos mais agressivos, mas eu acho totalmente o contrário, por ser uma experiência benéfica, os alunos sempre aprovam (Professor 6).

Relacionar lutas com questões de violência é um estigma consolidado no ambiente escolar, visto que a sociedade as classifica como uma forma de provocar confusões, assimilando o conteúdo a uma espécie de briga (OLIVIER, 2000). Estudos também apresentaram a relação do conteúdo de lutas com violência, tal como Rodrigues et al. (2017), ao conduzirem uma investigação sobre a percepção de dirigentes escolares sobre o conteúdo de lutas na escola. Os autores mencionam a preocupação dos participantes com algum estereótipo referente à violência, sendo que, se o profissional não souber conduzir o conteúdo, pode gerar agressividade nos alunos. Em estudo similar, Rufino e Darido (2015) encontraram também fatores relacionados à violência e relataram que isso deriva da falta de conhecimento da sociedade sobre o tema, dificultando sua inserção no ambiente escolar. 
A resposta do Professor 5 é marcante, pois relata como o estereótipo de relacionar lutas com violência é real em distintos contextos. O professor relata os cuidados que se deve ter no ensino das lutas, declarando que para a sua intervenção foi necessário o envio de bilhetes aos pais ou responsáveis pelos alunos, de modo a buscar respaldo para justificar o conteúdo à comunidade escolar, declarando que, mesmo assim, sofre restrições, conforme o seu relato,

Tem pais que acham que eu estou estimulando brigas, como ocorreu com um pai, dizendo que não queria o filho dele participando, esse aluno era o que mais brigava na Educação Física, e esse pai falou que as lutas estão estimulando a violência. Eu falei que vou ensinar ele a se controlar, mas assim, era uma pessoa muito ignorante nesse sentido, então tive que deixar só o filho dele fora da aula infelizmente, mas ele era o que mais precisava. Eu acho que tem preconceito, mas não são de todos, e como tenho bastante experiência, me preparo antes, mando bilhetes a respeito de que iremos aprender sobre lutas, já sabendo como é a realidade da comunidade, a exigência que os pais têm (Professor 5).

A constatação do Professor 5 corrobora com o estudo de Nascimento e Almeida (2007), que apresentou menções de violências nos professores investigados, como também justificaram que a violência é um tema presente na sociedade e a escola igualmente não está imune. Pode-se mencionar que tal preocupação com a violência se tornou banal/ para tanto, cabe à escola ser um dos mecanismos de informação e aprendizagem para a abordagem do tema. Autores apresentam que o ensino das lutas pode auxiliar a romper com a relação luta e violência, discutindo o conteúdo com os alunos no intuito de refletir sobre as questões relacionadas a estes conflitos no convívio social (OLIVIER, 2000; RUFINO; DARIDO, 2013; GALATTI; CIRINO; SCAGLIA, 2015; KURNIERZ et al., 2017).

Os investigados apresentaram conhecimento perante o conteúdo e, com isso, demonstraram certa preocupação ao tematizar lutas, porém, isso não os impediu de abordar o conteúdo e refletir sobre os paradigmas que as permeiam os quais devem ser rompidos por meio de estratégias de ensino que explorem a diversidade de um conteúdo polissêmico em significado e manifestações.

\section{O jogo como estratégia de ensino}

O jogo é um fenômeno complexo, sua compreensão se processa quando se joga e no contexto em que é utilizado; depende de jogadores, devendo ter sentido e significado, simulando o real e principalmente seduzindo a criança (BROUGÈRE, 1998). Ao jogar, pode-se observar a personalidade dos alunos (os sentimentos e as habilidades), a movimentação entre a realidade e o faz de conta, como também possibilidades lúdicas e pedagógicas, que fomentam o processo de ensino e de aprendizagem (SUITS, 1967; CHÂTEAU, 1987). 
Todos os participantes responderam utilizar os jogos de oposição como estratégia de ensino para tematizar as lutas em suas aulas. Tais argumentos se consolidam pelo fato de os investigados relatarem o envolvimento dos alunos nas aulas com jogos, sentindo-se desafiados pelas situações de confronto, como pondera um participante:

Utilizo jogos de oposição como estratégia, faço muitas situações em que os alunos têm que empurrar e tocar, elementos básicos das lutas, mas que tem significado, os alunos participam, eles adoram, o conteúdo acontece, tenho minhas limitações, mas com o jogo consigo ensinar um pouco de lutas para eles (Professor 3).

Gomes (2008) classifica os jogos de oposição como uma compilação de características das lutas, como ataque e defesa ocorrendo simultaneamente e o alvo sendo o adversário. Estas características ocorrem pela lógica regida no jogo, configurando-se na oposição. Esta lógica pode ser observada na narrativa do Professor 1,

Como exemplo dos jogos que eu trabalhava, colocava dois alunos em um círculo com o objetivo de tirar o adversário para fora do círculo. Eles tinham que se empurrar e puxar. É um jogo simples, mas que trabalha com elementos das lutas de agarre, como por exemplo o sumô (Professor 1).

Pode-se perceber que a professora de Educação Física atribui a lógica de oposição no jogo mencionado, além de características específicas das lutas de agarre. A relação que o jogo apresenta com a luta se encontra no ambiente que se desenvolve. Nesse ambiente existe a representação, pelos adversários assumirem o papel de lutadores de sumô; o desafio em tentar superar o oponente; o desequilíbrio, em sair da comodidade, pois as ações ocorrem simultaneamente; e a imprevisibilidade, pois não se sabe quem vencerá (FREIRE, 2002; SCAGLIA et al., 2013).

Os professores apresentaram diferentes opiniões sobre o conceito de jogo, as quais versaram sobre o jogo como conteúdo, uma estratégia de ensino e, até mesmo, uma brincadeira. Esta polissemia de significados pode ser atribuída ao contexto em que ocorrerá o jogo, como relata uma das professoras investigadas:

Eu acredito que o jogo tem vários significados, é um conteúdo, uma estratégia de ensino para trabalhar tal conteúdo, uma brincadeira, enfim, ele acontece de várias maneiras, em vários cenários diferentes. E eu utilizo o jogo no meu planejamento, tanto como conteúdo, quanto uma estratégia para ensinar nos demais conteúdos, como as lutas (Professor 1).

Este relato corrobora com estudos que apresentam uma conceituação polissêmica do jogo, mas se reportando ao contexto da Educação Física (REVERDITO; SCAGLIA, 2007; LEONARDO; SCAGLIA; REVERDITO, 2009; SCAGLIA et al., 2013). A gama de possibilidades de utilizar o jogo nas aulas se remete ao comprometimento do docente em saber como utilizá-lo corretamente, pois muitos educadores fazem uso indevido, como uma forma de distração, deixando as crianças livres, além de uma forma de chantagem, 
de modo que o professor possa aplicar conteúdos que não conseguiu ensinar (BROUGÈRE, 1998; FREIRE, 2002).

Tal exposto se consolida em estudos que retratam o uso indevido do jogo, negligenciando suas potencialidades (BROUGÈRE, 1998; FREIRE, 2002). O jogo apenas como uma distração ou sem um findar pedagógico não necessita de um educador para mediar, pois acontece em diferentes circunstâncias; seus personagens são os alunos, as regras e o ambiente são determinados por eles próprios (FREIRE, 2002). No jogo, deve haver um equilíbrio entre os aspectos lúdicos e pedagógicos, mas sempre com seriedade a quem joga; assim, podem ocasionar o prazer pelo sucesso, como também, reflexões sobre o fracasso. Ao mesmo tempo, a criança se prepara para novos desafios no domínio do jogo e na vida real (CHÂTEAU, 1987).

Por outro lado, os participantes foram questionados sobre os benefícios de se ensinar lutas por meio do jogo e as respostas mais mencionadas foram: interação entre os alunos; diversidade cultural; valências físicas; habilidades motoras; divertimento; autonomia; e criatividade. No relato de um dos professores de Educação Física, pode-se observar tais benefícios supramencionados:

De imediato seria o divertimento, mesmo se fosse apenas isso já é muito importante para os alunos. Além disso, tem a diversidade cultural, pois conhecem vários tipos de lutas e aprendem a lidar com o diferente. A autonomia para realizar as atividades, como também fazem questionamentos sobre as aulas [...] entendem a lógica do jogo, como criar estratégias [...], ampliando seus movimentos (Professor 5).

Em consonância ao relato do professor, é notória a contribuição que o ensino das lutas por meio do jogo favorece os alunos. Todavia, os seis professores de Educação Física compreendem que, utilizando o jogo de maneira séria e sistematizando o ensino das lutas, o respaldo e os benéficos se concretizam. Pode-se mencionar que o jogo para os professores investigados corrobora com a literatura apresentada em ser complexo. Torna-se um meio para ensinar os conteúdos, no caso, as lutas, para o que deve-se ter um olhar de seriedade, juntamente com a ludicidade, equilibrando os aspectos de diversão e os pedagógicos para obter resultados junto aos alunos.

\section{Sistematização do conteúdo de lutas}

O ensino das lutas requer sistematizações que atentam à diversidade de manifestações, sendo abordados nas dimensões conceituais, atitudinais e procedimentais. Para tanto, os professores investigados apresentaram, em suas narrativas, as sistematizações que adotaram para tematizar as lutas por meio do jogo.

Os Professores 2 e 5 sistematizaram o conteúdo por um período de aproximadamente um mês ao ano. Esta sistematização ocorreu mediante à apresentação dos conceitos 
das lutas, a qual aconteceu superficialmente em sala: realizaram pesquisas na internet, ressaltaram a importância de atribuir atitudes para os alunos com relação às brigas e ao preconceito, e elaboraram jogos de oposição com as características de alguma modalidade de lutas. Os investigados ainda relataram que convidam professores ou, até mesmo, alunos que praticam lutas para fazer uma aula mais específica.

A sistematização apresentada pelos Professores 2 e 5 atende as três dimensões dos conteúdos propostas pelos Parâmetros Curriculares Nacionais (BRASIL, 1998), quais sejam: a atitudinal; a procedimental; e a conceitual. A intervenção com as lutas é respaldada pelos conhecimentos ora apresentados na Base Nacional Comum Curricular (BRASIL, 2017) e em estudos que evidenciam os jogos de oposição. Na literatura são encontradas investigações que apresentam sistematizações similares, aquelas dimensionadas pelos professores investigados, as quais priorizam o jogo, as características da luta, além das dimensões conceituais e atitudinais que as lutas englobam (CIRINO; PEREIRA; SCAGLIA, 2013; GOMES et al., 2013; PEREIRA et al., 2017).

Por outro lado, os Professores 1, 3 e 6 sistematizavam o conteúdo, priorizando o jogo e as atitudes. Tratavam o jogo seriamente e realizavam reflexões referentes às condutas morais que as lutas podem gerar. Nesse sentido, por mais que os três participantes apresentassem o conteúdo em forma de blocos, em aproximadamente dez aulas, ainda houve a necessidade de apresentar os conteúdos conceituais aos alunos. Autores relatam que as histórias, as fábulas e a filosofia das artes marciais são riquíssimas, um patrimônio cultural dos povos e não apresentar esta gama de significados é uma forma de reducionismo do conteúdo (FETT; FETT, 2009; CORREIA; FRANCHINI, 2010; RUFINO; DARIDO, 2012; CORREIA, 2015; LOPES et al., 2016).

Por fim, o Professor 4 prioriza somente o jogo, ministrando o conteúdo em aproximadamente um mês e organizando seus jogos de oposição com as características das variadas modalidades de lutas. Assim como os professores 1, 3 e 6, o ensino das lutas deve priorizar também os conceitos e as atitudes, pois com isso irá potencializar o ensino e os jogos terão mais significado, além dos movimentos priorizados. Scaglia e Gomes (2011) priorizam os conteúdos em consonância ao jogo. Os autores discorrem que durante o jogo pode-se atribuir conceitos e atitudes, pois ele propicia reflexões antes, durante e após sua realização. Nesse sentido, o jogo, os conceitos e os aspectos atitudinais estão correlacionados, devendo ser apresentados e discutidos com os alunos.

Todos os participantes relataram que o tempo para aplicar o conteúdo é curto e corrido, pois, além de tematizar lutas, devem também abordar muitos outros conteúdos, que estão dispostos no plano de ensino. Com isso, pode-se justificar o porquê de algumas sistematizações apresentarem falhas, como relata o Professor 3, "O tempo é curto, apenas algumas aulas, aí tenho que dar uma corrida para poder trabalhar os demais conteúdos". É notória essa preocupação dos professores na distribuição dos conteúdos e no atendimento aos objetivos propostos. Para tanto, não é determinado o tempo escolar em que 
os professores trabalharão com determinado conteúdo no sistema estadual de educação de Santa Catarina. Desse modo, fica a critério do professor realizar sua própria organização, observando quantas aulas distribuirá para cada conteúdo estabelecido pela Proposta Curricular de Santa Catarina (2014).

No que se refere ao sistema de avaliação, os seis participantes foram similares em indicar avaliação prática (participação dos alunos) e avaliação teórica (provas, trabalhos e pesquisas). Os professores relataram que o sistema de avaliação adotado se pauta no sistema estadual de Santa Catarina, como discorre um dos professores entrevistados:

Minha avaliação é por meio de trabalhos e pesquisas, a participação dos alunos nas aulas e por uma prova teórica. Aqui na rede estadual de Santa Catarina é solicitado três avaliações, sendo: trabalhos, avaliação teórica e prática. Sempre trabalho em cima disso (Professor 3).

Pode-se mencionar que os participantes se pautam no sistema de avaliação da rede estadual de educação de Santa Catarina. Porém, os critérios avaliativos não foram mencionados, como, por exemplo, quais critérios são priorizados na avaliação prática. Nesse sentido, autores mencionam o que pode ser observado e avaliado do aluno por meio do jogo, mediante as tomadas de decisão nas situações-problema enfrentadas pelos discentes, pelos questionamentos para que o aluno reflita sobre suas decisões, além dos momentos oportunizados em que o aluno apenas discorra sobre a aula (SCAGLIA; GOMES, 2011; RUFINO; DARIDO, 2012; LACERDA et al., 2015; LEONARDI et al., 2017).

Referente ao método de avaliação por trabalhos e pesquisas, os participantes apresentaram como estratégias: roteiros de pesquisas; curiosidades sobre as lutas; conhecimento sobre lutadores e criadores das modalidades de luta. Assim, instigar o aluno a buscar conhecimentos para além das aulas pode potencializar os processos de ensino e de aprendizagem, visto que é extremamente necessário despertar a curiosidade dos alunos sobre o tema (RUFINO; DARIDO, 2012; PEREIRA et al., 2017). Com relação à avaliação por meio de provas teóricas, também não foram apresentados os critérios e como são elaborados pelos professores. Apenas mencionaram que as avaliações são realizadas somente para os estudantes dos anos finais do ensino fundamental. Organizar uma prova que atenda os conceitos das lutas é extremamente complexo, visto a gama de possibilidades que as lutas oferecem, cabendo ao professor julgar quais conceitos são necessários para organizar a avaliação.

É imprescindível ressaltar que a diretriz curricular do estado de Santa Catarina para a Educação Física dispõe de um cunho avaliativo voltado ao caráter formativo dos alunos, rompendo modelos avaliativos reducionistas, os quais priorizam quantificações e desempenho físico. Portanto, deve-se valorizar os enfoques cognitivo, crítico-social, psicológico, afetivo e o desenvolvimento motor; diante disso, há priorização da formação integral dos alunos também respaldada pelas dimensões dos conteúdos - conceitual, atitudinal e procedimental (SANTA CATARINA, 2019). 
Deste modo, é possível afirmar que a diversidade de ações desempenhadas pelos professores no intuito de oportunizar o ensino das lutas aos alunos pode romper os paradigmas inseridos na escola, visto o impacto que as lutas proporcionam na sociedade, bem como pela sua diversidade cultural, além de estar respaldado na legislação como um dos conteúdos da Educação Física escolar. Ademais, ojogo, como estratégia apresentada pelos professores de Educação Física investigados, torna-se um meio eficaz para abordar as lutas, reconhecida a escassez de professores a inseri-las em suas propostas pedagógicas. Todavia, o jogo como situação de aprendizagem pode promover o enriquecimento da Educação Física, diversificando os espaços de aprendizagem e trazendo para a realidade escolar conceitos e atitudes para além da prática.

\section{Considerações finais}

O ensino das lutas como conteúdo da Educação Física escolar é relevante, visto os resultados apresentados pelos participantes deste estudo, os quais sistematizam o conteúdo em suas aulas, utilizando o jogo como estratégia de ensino. A relação das lutas com o jogo se mostrou um mecanismo que atende o desenvolvimento apropriado, no tratamento pedagógico desse conteúdo, mesmo com os professores apresentando limitações nas sistematizações. Para os participantes, mesmo relatando possíveis restrições, o conteúdo foi contemplado e apresentado, tendo o jogo como uma estratégia de ensino.

Os resultados do estudo indicam que os docentes investigados apresentam conhecimento sobre as lutas. No entanto, pode-se destacar que esse conhecimento poderia ser ampliado com a discussão com os pares, bem como ser diversificado o ensino por meio de estratégias que conduzam o aluno ao aprendizado sobre a realidade e uso das lutas como desenvolvimento físico e intelectual. De fato, o jogo se tornou a estratégia mais evidente nos relatos dos professores, porém, o jogo de oposição foi aquele que se destacou nas narrativas. Todavia, pela amplitude que o jogo evidencia, outras formas de aprendizagem poderiam ser dimensionadas pelos docentes, no intuito de que as aulas não permaneçam apenas na prática sem olhar para a curiosidade que as lutas despertam nos alunos.

Embora os professores tenham apresentado detalhadamente as sistematizações para o ensino das lutas, acredita-se que a efetivação do conteúdo em anos escolares seguintes, apresente uma sequência pedagógica, ou seja, que a cada ano escolar fosse privilegiada a complexidade do conteúdo. Todavia, pode-se destacar que o conteúdo lutas inserido nas propostas pedagógicas e nos planos de ensino dos professores ainda apresenta restrições quanto ao seu desenvolvimento, tendo em vista a questão do espaço físico e dos equipamentos, entre outros fatores. Além disso, geralmente a formação continuada de professores, talvez não promova aos docentes o conhecimento sobre este conteúdo, de modo que ele seja tematizado na escola. 
O estudo apresenta como limitações o número reduzido de participantes, a não observação das aulas e não ter contato com o planejamento dos professores, visto que estes fatores podem ser considerados importantes para investigar como as aulas ocorrem por meio do jogo. Além disso, outra limitação se estabelece nas avaliações educacionais, podendo ser explorado como elas se materializam durante o conteúdo de lutas. Mediante o exposto, recomenda-se futuras investigações com métodos de observação de aulas e análise de documentos (plano de ensino e avaliações), além de estudos com foco no aluno durante as aulas de lutas.

Considera-se o ensino das lutas, utilizando o jogo como estratégia pedagógica mencionado pelos participantes e por pesquisadores, apropriado para a tematização do conteúdo no contexto escolar, capaz de romper os paradigmas que assolam as lutas. Ressalta-se, ainda, a importância do conteúdo como manifestação da cultura corporal, historicamente constituída pelos povos de todo mundo, cabendo sua inserção efetiva na Educação Física escolar.

Ressalta-se que, para os professores investigados, este estudo pode contribuir para a compreensão e o aprimoramento do conhecimento sobre o ensino das lutas, com respaldo do fenômeno jogo enquanto estratégia de ensino, auxiliand o na ruptura de paradigmas e possíveis restrições ao ensinar o conteúdo no âmbito escolar. Por fim, para a comunidade científica, esta pesquisa apresentou um retrato do ensino das lutas em escolas estaduais catarinenses, trazendo à tona o entendimento sobre o contexto educacional e promovendo o contributo para redimensionar as práticas dos professores, além de ser um novo referencial para embasar futuras investigações sobre o ensino das lutas no ambiente escolar.

Recebido em: 21/11/2019 e Aprovado em: 09/07/2015

\section{Referências}

ALENCAR, Y. O.; SILVA, L. H.; LAVOURA, T. N.; DRIGO, A. J. As lutas no ambiente escolar: uma proposta pedagógica. Revista brasileira Ciência e Movimento, Brasília, v. 23, n. 3, p. 53-63, 2015.

BARDIN, L. Análise de conteúdo. Lisboa: Edições 70 Ltda, 1977.

BRASIL. Ministério da educação. Base Nacional Comum Curricular: Educação é a base. Brasília: MEC, 2017.

BRASIL. Secretaria de Educação Fundamental. Parâmetros Curriculares Nacionais: Educação Física. Brasília: MEC/SEF, 1998.

BREDA. M.; SCAGLIA, A. J.; PAES, R. R.; GALATTI, L. R. Pedagogia do esporte aplicada às lutas. São Paulo, SP: Phorte, 2010.

BROUGÈRE, G. Jogo e Educação. Porto Alegre: Artmed, 1998. 
CAILLOIS, R. Os jogos e os homens: a máscara e a vertigem. Lisboa: Cotovia, 1990.

CHÂTEAU, J. O jogo e a criança. São Paulo: Summus, 1987.

CIRINO, C.; PEREIRA, M. P. V. C.; SCAGLIA, A. J. Sistematização dos Conteúdos das Lutas para o Ensino Fundamental: uma proposta de ensino pautada nos jogos. Revista Mineira de Educação Física, Viçosa, ed. Especial, n. 9, p. 221-227, 2013.

CORREIA, W. R. Educação Física Escolar e Artes Marciais entre o combate e o debate. Revista Brasileira de Educação Física e Esporte, São Paulo, v. 29, n. 2, p. 337-344, 2015.

CORREIA, W. R.; FRANCHINI, E. Produção acadêmica em lutas, artes marciais e esportes de combate. Motriz, Rio Claro, v. 16, n. 1, p.1-9, 2010.

FETT, C.; FETT, W. Filosofia, ciência e a formação do profissional de artes marciais. Motriz, Rio Claro, v.15, n.1, p. 173-184, 2009.

FREIRE, J. B. O Jogo entre o riso e o choro. São Paulo: Autores Associados, 2002.

GALATTI, L. R.; CIRINO, C.;SCAGLIA, A. J. Reflexões metodológicas do ensino para o processo de iniciação esportiva das lutas. In: NASCIMENTO, J. V.; SOUZA, E. R.; RAMOS, V.; ROCHA, J. C. S. (Orgs.). Educação

Física e Esporte: convergindo para novos caminhos... Florianópolis: UDESC, 2015. p. 489-511.

GOMES, M. S. P.; MORATO, M. P.; DUARTE, E.; ALMEIDA, J. J. G. Ensino das lutas: dos princípios condicionais aos grupos situacionais. Movimento, Porto Alegre, v.16, n. 2, p. 207-227, 2010.

GOMES, N. C.; BARROS, A. M.; FREITAS, F. P. R.; DARIDO, S. C.; RUFINO, L. G. B. O conteúdo das lutas nas séries iniciais do ensino fundamental: possibilidades para a prática pedagógica da Educação Física escolar. Motrivivência, Florianópolis, v. 5, n. 41, p. 305-320, 2013.

GOMES, M. S. P. Procedimentos pedagógicos para o ensino das lutas: contextos e possibilidades. 2008. 139 f. Dissertação (Mestrado em Educação Física) - Faculdade de Educação Física, Universidade Estadual de Campinas, Campinas, 2008.

KUSNIERZ, C.; CYNARSKI; W. J.; GORNER; K. Social reception and understanding of combat sports and martial arts by both school students and adults. Journal of Martial Arts Anthropology, Strzyzów, v. 17, n. 1, p. 30-37, 2017.

LACERDA, R. P.;SILVA, J.P.; LOVISI, A.; MOURÃO, L. N. Ensino de lutas: relatos de uma experiência na rede pública. Salusvita, Bauru, v. 34, n. 3, p. 437-453, 2015.

LEONARDI, T. J.; GALATTI, L. R.; SCAGLIA, A. J.; MARCO, A.; PAES, R. R. Pedagogia do esporte: sinalização para a avaliação formativa da aprendizagem. Pensar a Prática, Goiânia, v. 20, n. 1, p. 216-229, 2017.

LEONARDO, L.; SCAGLIA, A. J; REVERDITO, R. S. O Ensino dos Esportes Coletivos: Metodologia pautada na Família dos Jogos. Motriz, Rio Claro, v. 15, n. 2, p. 236-246, abr/jun. 2009.

LOPES, H.; VICENTE, A.; SIMÕES, J.; VIEIRA, M.; FERNANDO, C. O processo pedagógico nos esportes de combate. Journal of Sport Pedagogy and Research, Lisboa, v. 2, n. 3, 48-52, 2016.

NASCIMENTO, P. R. B.; ALMEIDA, C. A tematização das lutas na Educação Física Escolar: restrições e possibilidades. Movimento, Porto Alegre, v. 13, n. 3, p. 91-110, 2007.

NEGRINE, A. Instrumentos de coleta de informações na pesquisa qualitativa. In: MOLINA NETO, V:; TRIVIÑOS, A. N. S. (Orgs.). A pesquisa qualitativa na educação física: alternativas metodológicas. Porto Alegre: Editora Universidade/UFRGS/Sulina; 1999. p. 61-93. 
OLIVIER, J. C. Das brigas aos jogos com regras: enfrentando a indisciplina na escola. Porto Alegre: Artmed, 2000.

PEREIRA, M. P. V. C.; CIRINO, C.; CORREA, A. O.; FARIAS, G. O. Lutas na escola: sistematização do conteúdo por meio da rede dos jogos de lutas. Conexões, Campinas, v. 15, n.3, p. 338-348, 2017.

REID, H. CROUCHER, M. O Caminho do Guerreiro: o paradoxo das artes marciais. São Paulo: Cultrix, 1983.

REVERDITO, R. S.; SCAGLIA, A. J. A gestão do processo organizacional do jogo: uma proposta metodológica para o ensino dos jogos desportivos coletivos. Motriz, Rio Claro, v. 13, nº 1, p. 51-63, 2007.

RODRIGUES, A. I. C.; BAIÃO JUNIOR, A. A.; ANTUNES, M. M.; ALMEIDA, J. J. G. The perception of school directors in the city of Jaguariúna about combat sports. Journal of Physical Education, Maringá, v. 28, n. 29, 2017.

RUFINO, L. G. B.; DARIDO, S. C. Pedagogia do esporte e das lutas: em busca de aproximações. Revista brasileira Educação Física e Esporte, São Paulo, v.26, n.2, p.283-300, 2012.

RUFINO, L. G. B.; DARIDO, S. C. Ensino das lutas nas aulas de educação física: análise da prática pedagógica à luz de especialistas. Journal of Physical Education, Maringá, v. 26. n.4, 2015.

RUFINO, L. G. B.; DARIDO, S. C. Possíveis diálogos entre a educação física escolar e o conteúdo das lutas na perspectiva da cultura corporal, Conexões, Campinas, v. 1, n. 1, p. 145-170, 2013.

SANTA CATARINA. Governo do Estado, Secretaria de Estado da Educação. Proposta Curricular de Santa Catarina: formação integral na educação básica. Estado de Santa Catarina, Secretaria de Estado da Educação, 2014.

SANTA CATARINA. Governo do Estado, Secretaria de Estado da Educação. Currículo base da educação infantil e do ensino fundamental do território catarinense. Estado de Santa Catarina, Secretaria de Estado da Educação, 2019.

SCAGLIA, A. J.; GOMES, M. S. P. Projeto de Extensão Crescendo com as Lutas. Limeira: FCA/UNICAMP, 2011.

SCAGLIA, A. J.; REVERDITO, R. S.; LEONARDO, L.; LIZANA, C. J. R. O ensino dos jogos esportivos coletivos: as competências essenciais e a lógica do jogo em meio ao processo organizacional sistêmico. Movimento, Porto Alegre, v. 19, n 4, p. 227-249, 2013.

SUITS, B. What is a game? Philosophy of Science, Chicago, v. 34, n. 2, p. 148-156, 1967. 